\title{
HISTÓRIAS DE VIDA DE MULHERES E SAÚDE DA FAMÍLIA: ALGUMAS REFLEXÕES SOBRE GÊNERO ${ }^{1}$
}

\author{
Ana Priscila de Oliveira Benites e Neuzi Barbarini \\ Faculdade Evangélica do Paraná, Curitiba, Brasil
}

\begin{abstract}
RESUMO: Frente às imbricações de gênero na saúde, este artigo traz a discussão desse conceito no âmbito da Estratégia Saúde da Família, a partir das histórias de vida de duas mulheres usuárias de uma Unidade de Saúde PSF. A construção sócio-histórica de gênero, seu caráter relacional e hierarquizante possibilitaram perceber, ao se olhar para as trajetórias dessas mulheres, que as permanências e transformações de gênero significadas no cotidiano também se reproduzem na esfera da saúde. Assim, ao não abarcar as subjetividades femininas e colocar a mulher num lugar maternal, a saúde a oprime enquanto Sujeito histórico; de modo que na práxis em Saúde da Família, o enfoque de gênero se coloca como indispensável na busca da integralidade.
\end{abstract}

PALAVRAS-CHAVE: mulher; gênero; história de vida; saúde da família.

\section{WOMEN'S HISTORIES OF LIFE AND FAMILY HEALTH: SOME CONSIDERATIONS ABOUT GENDER}

\begin{abstract}
Ahead the gender imbrications in health, this article intends to discuss the concept of gender inside the Family Health Strategics Program (PSF) considering the trajectory of life of two women followed up in a PSF Health Unit. Considering the social and historical construction of gender and its hierarchical and relational aspects, we could verify, looking at the life trajectory of those women, that permanencies patterns and gender transformations in their daily lives also appear in the health field. In this manner, when the female subjectivities are not included and only the motherhood is considered, the health field can be an oppressor of the female historical subject. Thus, the Family Health praxis must consider the gender meanings as an essential aspect to understand the whole human subject.
\end{abstract}

KEYWORDS: woman; gender; history of life; family health.

"A experiência das mulheres contém sempre a experiência de outras mulheres e esta experiência vem sendo transmitida
oralmente, por gesto, olhares e narrativas. As mulheres foram e são construídas com palavras." (Meneghel et al., 2005, p. 113).

\section{Introdução}

Este artigo procura discutir as questões de gênero inseridas em histórias de vida de mulheres, com a temática da Saúde da Família.

O Programa Saúde da Família (PSF) foi criado em 1994 pelo Ministério da Saúde, para reorientar o modelo assistencial médico-hospitalocêntrico vigente na saúde pública. Para tanto, preconiza o desenvolvimento de ações interdisciplinares, intersetoriais e de promoção à saúde, em sintonia com os princípios do Sistema Único de Saúde (SUS), dentre os quais se destaca a busca pela integralidade da atenção ${ }^{2}$. O trabalho no PSF se volta para um território específico e foca o grupo familiar em seus aspectos afetivos e socioculturais, de maneira que o processo saúde-doença passa a ser concebido a partir de uma visão sistêmica; e, no qual, a dimensão relacional do profissional de saúde ganha ênfase no trabalho interdisciplinar e no vínculo com a comunidade. Hoje o programa tem sido denominado de Estratégia Saúde da Família (ESF) para a implementação dos preceitos da Reforma Sanitária. ${ }^{3}$

Ao alocar a integralidade como princípio, a ESF propõe uma mudança paradigmática no trabalho em saúde. A integralidade se contrapõe "à abordagem fragmentária e reducionista dos indivíduos" (Alves, 2005 , p. 42) - o que implica antes uma mudança pessoal, ideológica. Posto o desafio, a prática aponta que o caminho é longo, mas que, inevitavelmente neste trilhar, os profissionais de saúde precisarão olhar para as questões de gênero - já tão imbricadas no uso dos próprios conceitos: saúde e família. Elas aparecem, por exemplo, na elaboração de programas de saúde específicos para as mulheres e na conceituação do que é família.

$\mathrm{O}$ interesse pelo tema surgiu da vivência de dois anos em uma Unidade de Saúde PSF, na qual foram 
desenvolvidas ações com grupos, atendimentos e visitas domiciliares. Na comunidade, as questões de gênero ressoavam a todo instante em frases do tipo: "Ah, não posso vir nesse horário, pois tenho que fazer almoço pro meu marido...".

À história oficial das mulheres descrita nos livros, soma-se uma construída no anonimato do dia-a-dia, registrada na biografia de cada mulher. Essa história, única, faz parte e também escreve a história do todo, do universo feminino. Ouvi-las é dar voz ao coração de quem muitas vezes vive batalhas diárias, silenciosas, sofridas. Desse modo, como as questões de gênero se engendravam nas histórias de vida daquelas mulheres?

Não se trata aqui de uma intervenção preocupada com a amostragem, mas, antes, em ouvir as histórias e sentimentos acerca de ser mulher, com gênero como categoria de análise (Scott, 1990), aliada às contribuições teóricas da Psicologia Social, da Antropologia e da abordagem Familiar Sistêmica, num olhar interdisciplinar sobre a Saúde da Família. O objetivo é buscar os significados de ser mulher através de histórias de vida e, a partir destas, refletir as implicações de gênero no âmbito da saúde.

\section{Feminismo (s) e Psicologia (s) - Considerações Acerca de Gênero:}

Se, até muito recentemente, "o 'desenvolvimento humano' referia-se ao desenvolvimento masculino e o desenvolvimento das mulheres era definido pelos homens de suas vidas" (Carter, McGoldrick et al., 2001, p. 30), existe um processo histórico que modificou essa visão reducionista e incentivou a emancipação feminina. A maternidade como escolha e a inclusão na política são algumas das transformações alicerçadas pela entrada da mulher no mercado de trabalho e impulsionadas pelo Movimento Feminista - que emergiu no final da década de 60 nos países capitalistas, questionando a divisão tradicional de papéis sociais entre homens e mulheres. Foi neste contexto que o conceito de gênero surgiu, em oposição à naturalização biológica do que é ser homem e mulher, localizando o masculino e o feminino como construções socioculturais. Como um elemento constitutivo das relações sociais, também significa as relações de poder (Scott, 1990) e possui um caráter intrinsecamente relacional, pois o universo das mulheres faz parte do universo dos homens e viceversa (Araújo, 2005).

O feminismo configurou uma nova referência de ser mulher a partir do coletivo (Sarti, 2004). Na verdade, é preciso se falar em "feminismos" frente à diversidade das construções ideológicas existentes. Para a Antropologia, por exemplo, a análise do feminino requer a referência ao contexto que lhe dá significado, visto que as mulheres não são uma categoria universal senão pela projeção de nossas referências culturais (Sarti, 2004).

Diferentemente, a Psicologia, enquanto ciência que estrutura seu objeto de estudo como um ser genérico ('o homem') e que tradicionalmente tem se dito apolítica, nega o poder simbólico que contém e legitima a rígida categorização de homens e mulheres em estereotipias de papéis sociais (Fonseca, 1997), favorecendo, dessa forma, a manutenção do padrão masculino como referência. Não obstante, efervescidas pelo feminismo dos anos 70 , as questões de gênero deixaram de ser vistas como biológicas, e foram, em parte, incorporadas à Psicologia Social, embora o deslocamento do foco dos indivíduos aos processos sociais só veio a acontecer com a corrente construcionista na psicologia social, a partir do feminismo pós-modernista (Nuernberg, 2004).

Nas últimas décadas, a psicologia social crítica vem se empenhando em "engendrar interfaces com as demais ciências sociais, pensando os sujeitos humanos como produtos e produtores no/do universo social e cultural" (Nuernberg, 2004, p. 220). Tal compromisso requer uma atitude interdisciplinar de produção do conhecimento, o que se casa com a investigação de gênero e favorece a superação dos pressupostos universalistas da psicologia. Tarefa, contudo, que ainda se apresenta como um desafio - pois, ao se compreender o gênero como "componente/compositor da subjetividade", é preciso toda uma construção teórica para abarcar suas pluralidades e não somente sua incorporação aos estudos em psicologia (Siqueira, 1997, p. 277).

Nesse construir, a família possibilita um lócus privilegiado para o estudo de gênero enquanto categoria relacional, uma vez que é o primeiro núcleo socializador do indivíduo. As terapias familiares de abordagem sistêmica ${ }^{4}$ buscam compreender o ser humano através da sua história de vida familiar, nos seus aspectos intergeracionais e socioculturais. Todavia, elas já foram criticadas pelas feministas por não analisarem as questões de gênero e poder incutidas em suas práticas, que traziam um sexismo implícito nas definições de família e de papéis familiares ${ }^{5}$. O questionamento do conceito de papéis sociais foi, sem dúvida, um dos aspectos que colaborou para flexibilizar a definição de família. No paradigma feminista, os terapeutas familiares passaram a criticar os pressupostos sexistas da existência de papéis apropriados para homens e mulheres, entendendo que esses "papéis" podem servir para normatizar e perpetuar as diferenças de poder entre os gêneros (Rampage \& Avis, 1998). Testoni e Tonelli (2006) também referenciam o caráter reducionista do termo, pois, uma vez que gênero não diz respeito à função, tampouco remete à atribuição de papéis masculinos ou femininos (estes devem ser sempre referendados como construções histórico-culturais). 


\section{Alguns Dados Sobre as Mulheres Brasileiras:}

De acordo com o Instituto Brasileiro de Geografia e Estatística (IBGE), as mulheres já constituem mais de $50 \%$ da população brasileira. Ser mulher, antes sinônimo de mãe integral e dona de casa - uma vida dedicada à família, já não é mais a regra predominante; hoje, inserida nos espaços públicos, tem mais oportunidades de realização pessoal, o que implica também maiores responsabilidades. Pesquisa da Fundação Perseu Abramo (FPA) ${ }^{6}$ revela que a maioria das mulheres "considera de fundamental importância a inserção no mercado de trabalho, a independência econômica, a possibilidade de tomar decisões e agir livremente, dissociando, pois, sua definição de gênero da idéia de maternidade" (Rago, 2004, p. 33). Se bem que as condições sócio-históricas que delegaram as funções de cuidado à mulher por vezes ainda impõem limites ou impossibilidades para sua inserção e/ou permanência no mercado de trabalho.

Os fatores que influenciam a decisão da mulher de entrar ou permanecer no mercado de trabalho não dependem somente de uma demanda externa e das suas qualificações para atendê-lo, mas, antes, da complexa articulação das suas características pessoais e familiares, tais como: a posição na família, a necessidade de prover ou complementar o sustento do lar e, também, a estrutura e o ciclo de vida familiar (Fundação Carlos Chagas). Dados da pesquisa da FPA quanto à repartição das tarefas domésticas atestam que, em $96 \%$ dos domicílios pesquisados, a principal responsável por essas tarefas era uma mulher. Sorj (2004) comenta que, independentemente da situação familiar ou laboral, o padrão de atribuir as responsabilidades domésticas e familiares às mulheres ainda se constitui numa das principais convergências da experiência feminina.

Essa pesquisa aponta que $65 \%$ das brasileiras avaliam que a vida das mulheres melhorou nos últimos 30 anos (Soares, 2004), embora ainda tenham que lidar com o peso das tarefas domésticas, o acúmulo de responsabilidades na criação dos filhos, a violência conjugal, etc. Enfim, é possível detectar que as mulheres têm sido os sujeitos ativos da mudança nas relações de gênero, mas nem sempre têm encontrado a contrapartida da equivalência masculina na divisão do trabalho doméstico e nos espaços públicos (Venturi \& Recamán, 2004).

\section{Mulheres e Saúde:}

No Brasil, em relação à saúde, a mulher ainda enfrenta dificuldades e desigualdades regionais para: o acesso aos serviços, prevenção da gravidez indesejada, redução da taxa de mortalidade materna, dentre outras questões que a expõe a uma maior vulnerabilidade - como o não uso da camisinha -, ligadas em sua maioria aos valores morais da sociedade (Costa \& Silvestre, 2004).

Por razões fisiológicas e socioculturais, a saúde constitui uma esfera importante do universo feminino. Historicamente, os cuidados informais à saúde sempre foram exercidos pelas mulheres, e elas "tendem, muito mais do que os homens, a se definirem como pacientes e a buscarem ajuda" (Carter, McGoldrick et al., 2001, p. 58). Não por acaso, a força feminina se faz muito presente, tanto como recursos humanos, quanto como frequentadora dos serviços de saúde, principalmente na Atenção Básica. Dados da PNAD/20037 atestam que a maior parte da população que frequenta as Unidades de Saúde é feminina (IBGE, 2005).

No nível macropolítico, a atenção à saúde da mulher deu um passo importante com o Programa de Assistência Integral à Saúde das Mulheres (PAISM). Criado na década de 80 pelo Ministério da Saúde, visava ser uma política de atenção integral à saúde da mulher (Costa \& Silvestre, 2004). Se na prática ele não deslanchou, sua política de integralidade foi incorporada ao SUS com a Constituição de 1988, possibilitando outros programas para as mulheres ${ }^{8}$.

Em contrapartida, nem todas as estudiosas da temática feminina veem as políticas de atenção à mulher com bons olhos. Alegam que "os pronunciamentos oficiais sobre gênero, fazem parte das políticas macroeconômicas, as quais aumentam a desigualdade entre as mulheres" (Meneghel et al., 2005, p.112). Para elas, o conceito de gênero tem sido usado para esvaziar os movimentos populares e mudar o foco das desigualdades para as questões reprodutivas; entendem que são os grupos um caminho de resistência coletiva que permitem às mulheres resgatarem as estratégias de "empoderamento" que inventam e constroem no seu dia-a-dia.

Um outro olhar mostra que os programas de assistência à mulher - fragmentados nos seus cuidados por orientarem-se para uma parte, agravo ou função do corpo - distanciaram "o modelo de atenção à saúde do sentido estruturante da integralidade, ou seja, a concepção do sujeito como integral e indissociável em suas necessidades subjetivas e nas identificadas pelos serviços" (Costa \& Silvestre, 2004, p. 65). No entanto, em meio a contrastes, a experiência brasileira de atenção à saúde da mulher tem sido importante ao reconhecer sua complexidade e diversidade, indo além da esfera reprodutiva. Eis que a ESF surge como proposta de atenção integral à saúde que não se restringe à esfera da mulher, mas incorpora sua rede de relações, no caso, a família.

À guisa de reflexão, contudo, fica aqui uma observação sobre gênero e programas de saúde, sobretudo como a forma de trabalho pode vir carregada de uma visão reducionista: em alguns programas de Saúde da Família 
a mulher é incorporada na qualidade de gestante e como mãe, para o combate à desnutrição infantil. A incorporação da mulher como mãe não apenas indica a focalização de um grupo de risco, mas também assinala uma incorporação baseada em sua "função" na família (Farah, 2004, p. 14).

Por fim, a autora aponta a filosofia do PAISM, de atenção integral à saúde da mulher, como potencial de "empoderamento".

\section{Método}

Essa pesquisa qualitativa ateve-se na exploração do que significava ser mulher, a partir de entrevistas de histórias de vida. Nesta proposta, "as particularidades de cada história compõem determinada história social e coletiva dos sujeitos em determinado momento" (Narita, 2006 , p. 26). Aqui interessou-nos ouvir mulheres que nasceram antes do movimento feminista, para acompanharmos suas percepções desses últimos 30 anos. $\mathrm{Na}$ pesquisa qualitativa assume-se que "a inter-relação no ato da entrevista contempla o afetivo, o existencial, o contexto do dia-a-dia, as experiências e a linguagem do senso comum" (Minayo, 2004, p. 124); destarte, também nos preocupamos em resgatar e valorizar as trajetórias dessas mulheres. O norte deste trabalho foi a busca pelos sentidos de ser mulher - ou ainda, de subjetividades femininas.

Os sujeitos de pesquisa são duas mulheres, usuárias de uma Unidade de Saúde PSF, localizada num bairro da periferia de Curitiba, que frequentavam há mais de um ano o grupo de caminhada desenvolvido pela Residência em Saúde da Família. O grupo era uma atividade de promoção da saúde, composto em sua maioria por mulheres aposentadas e donas-de-casa, que foram convidadas a participar voluntariamente deste estudo. Pela convivência no grupo, tínhamos um bom vínculo com essas mulheres. Com cada uma foi realizada uma longa entrevista, com um breve roteiro de apoio (mas que de forma alguma limitasse a entrevistada), no qual o fio condutor foi o tema: mulher. As entrevistas foram gravadas, transcritas quando se cumpriu uma entrevista individual devolutiva para considerações - , e analisadas.

Como referencial de análise para os depoimentos utilizamos a hermenêutica-dialética proposta por Minayo (2004), que oferece a possibilidade de compreensão do sujeito a partir do seu contexto sóciohistórico.

\section{Resultados e Discussão}

Então mulher: quanta força há no seu corpo "dito" frágil, quantos desejos secretos guardados em seu ventre, quantas lágrimas escondidas em seu coração, quantos sonhos ainda anseiam seus olhos, quantos curativos precisam sua alma, quanta dor e alegria há pra contar em sua história?

Duas Trajetórias - dois sentidos de ser (de se fazer) mulher:

Lia: 60 anos. Caçula (tem um irmão sete anos mais velho). Três filhas (40, 38 e 34 anos) do primeiro casamento, que durou dezenove anos. Quatro netos. Recasada há catorze anos. Aposentada, recebe um salário mínimo. Estudou até $5^{\mathrm{a}}$ série, depois retomou os estudos, mas não terminou. Evangélica (já foi católica). Mora há 12 anos no bairro.

Lia é natural do interior de São Paulo, filha de um agricultor e uma costureira; vivia mudando de sítio com a família, pois não tinham terra própria. Da infância traz que os pais a menosprezavam, dizendo coisas do tipo: “Ah, essa menina não vale nada...”. Em meio a desavenças, contudo, ressalta um lado carinhoso do pai; da mãe, que era mais fechada, conta: "Ela era muito forte, muito batalhadeira .... E ao mesmo tempo era fraca - gostava do meu pai e meu pai não gostava dela" (pelo fato do pai ter amantes). Falava que antes de casar queria estudar, mas como os pais não a deixavam sair de casa, casou porque queria liberdade. Esse casamento, porém, foi o período em que mais sofreu: "Mas eu não podia largar dele por causa que depois nasceu as crianças. Então tive que dar um tempo até elas crescerem. Depois que elas cresceram eu pedi pra separar, ele não deixava eu separar". O marido era ciumento e tinha relacionamentos extraconjugais. Seu sonho era ser professora: "Resolvi casar, abandonei tudo, fui casar pra sofrer. Dai fui casar, ter filho, ficar doente, tudo, abandonei ser professora... "Chegou a dar aulas num grupo escolar do interior e queria ter voltado a estudar, não fosse o medo que sentia do marido, que não deixava:

Quando ele era solteiro, antes de casar, parecia muito bom. Quando ele casou que viu que o papel tava passado, que viu que eu era a mulher dele, então ele se valia daquilo, falava: você ta casada comigo, ta escrito aqui!

Com as filhas já crescidas, um dia arrumou um emprego de diarista, fez as malas e fugiu de casa (a filha menor ficou com seus pais). Apesar das dificuldades que enfrentou quando tomou essa atitude, dizia: "Graças a Deus sou livre! Minha liberdade chegou!". Nesse período, trabalhava a maior parte como doméstica e frequentava bailes pra se divertir. Ficou oito anos sozinha até conhecer o atual marido; alega que os homens eram mal-educados. Não tem um relacionamento próximo com o irmão; desentenderam-se quando os pais morre- 
ram. Por tudo que passou com o primeiro marido, tem raiva de homem. Gosta de ser mãe, mas se fosse agora seria mais carinhosa. Queria que as filhas tivessem feito faculdade, porém não quiseram. Para Lia, o momento mais bonito da sua vida foi quando voltou a estudar.

Rosa: 75 anos. Caçula de oito filhos. Viúva há dois anos (foi casada por 54 anos). Onze filhos (seis mulheres e cinco homens, com idades entre 55 e 34 anos); 21 netos e sete bisnetos. Dona-de-casa; recebe amparo social/Benéfico de Prestação Continuada (BPC) do INSS. Estudo básico (escola rural). Católica. Mora há um ano no bairro.

Natural de Minas Gerais, filha de um agricultor e uma dona-de-casa, Rosa e os irmãos desde muito cedo ajudavam com os afazeres no sítio. Muito trabalhadora, até hoje Rosa aprecia qualquer tipo de serviço, mesmo o mais pesado - não gosta de ficar parada. Do pai conta que era bravo, mas "paizão" e, da mãe, que era muito paciente: "Acho que eu puxei muito dela!". Sempre teve um bom relacionamento com os irmãos; diz que se dá bem com todo mundo. Rosa casou aos dezoito anos com um agricultor e, até vinte anos atrás, morava em sítio. Os filhos foram vindo; o marido ia para a roça e Rosa era a única responsável pelos afazeres domésticos, num período que não havia luz onde morava e roupa se lavava na bica. Sem um trabalho remunerado, era seu marido quem decidia o que poderia ou não comprar, inclusive o "comprimido" para não engravidar:

Acontece o seguinte, que meu velho que era uma pessoa sistemática, né! Que quando eu tinha cinco filhos eu queria tomar comprimido. Mas como eu não tinha acesso a dinheiro, lá tudo era na mão dele eu não tinha um tostão na minha mão! Não era igual hoje que você tem um posto de saúde você vai lá, você ganha comprimido, né! Aí falei pra ele: compra, eu vou tomar comprimido, porque chega de tanto trabalho, né; é muito trabalho pra gente! "Ai nada disso porque essa mulher que toma comprimido fica tudo doente ..., não sei quê!’” Não deixou. Ele não dava dinheiro, não tinha acesso a dinheiro...

Todos seus onze filhos nasceram de parto normal em casa; não teve nenhum aborto ou outra complicação. Diz ser uma benção de Deus. O fato mais marcante da sua vida foi quando a filha mais velha fugiu de casa para se casar - na época, seu marido não aceitava o namoro da filha - e, por causa desse episódio, Rosa ficou um bom tempo sem vê-la, o que a fez sofrer muito, pois o marido não deixava. Já uma grande emoção foi ver um filho e uma filha se formando na faculdade. De uma fé muito grande, Rosa adora rezar e servir à igreja. Hoje, mora com uma filha e cuida de uma netinha de sete anos, de um filho que se separou e não podia cuidar dela. Sente muito orgulho em ser mãe; sua felicidade são os filhos.

\section{"Mulher Tem Que Ser Forte"}

As subjetividades femininas emergem nas falas, nas lembranças vividas... Quase que tomam corpo na memória escrita. Contar a história de vida possibilita um encontro consigo mesmo; Rosa comenta que ter contado sua história a deixou mais leve, tirou um peso de dentro de si.

$\mathrm{Na}$ idiossincrasia de cada história, ser mulher implica múltiplos sentidos de gênero, que ora se encontram em ambas as trajetórias pelo compartilhar de um mesmo contexto sociopolítico. Rosa e Lia são mulheres de classes populares, que migraram do rural para o urbano e se encontram numa fase de revisão da vida, na qual, já avós, precisam lidar com o declínio fisiológico e perdas de entes queridos. Em seus relatos, significados de ser mulher emergem entrelaçados na esfera da saúde/sexualidade, na história intergeracional e na própria posição de gênero que, em distintos momentos, denota certo sofrimento pelo lugar socialmente "ocupado" como mulher e, em outros, impulsiona mudanças desse lugar.

Senhoras de terceira idade, Lia e Rosa trazem as marcas de uma moral sexual conservadora em relação à mulher - ambas casaram virgens e, naquela época, em suas famílias, não se conversava sobre sexualidade. Rosa ficou transtornada quando veio a primeira menstruação: "Lavava a calcinha, vestia molhada pra ninguém ver". E comenta:

Não é querer acusar ela, mas as mães naquele tempo não conversava com as filhas, a respeito de sexo, a respeito de menstruação... Assim, até chegar o tempo da gente ter e não saber de nada! É duro com as filhas! Ela não ajudava a gente assim; acho que é o sistema antigo, né! Ficava meio que uma barreira, não podia falar naquilo, né! Isso ai foi uma coisa que eu sofri bastante com isso!

No relacionamento sexual, Lia conta que seu primeiro marido era "bruto, tarado... E eu pensava que era assim mesmo..."; quando engravidou, tampouco sabia como era o parto: "Pensava que amanhecia com a criança do lado... Aprendi com a dor". Se, por um lado, Lia e Rosa buscaram se diferenciar de suas famílias de origem conversando com seus filhos sobre sexualidade, por outro mantiveram parte dos padrões que sustentam a lógica masculina de que se espera que a mulher detenha um maior controle sobre sua sexualidade (Testoni \& Tonelli, 2006). Quando, por exemplo, Rosa comenta sobre os direitos das mulheres:

Porque inclusive as minhas filhas tudo têm o direito delas.... Igual tem os direitos dos homens elas têm também, mas elas sabe respeitar eles como marido, né! Não dize que tem direito e pode ir pras farra; isso não, né! Tem que ter limite! 
Chacham e Maia (2004) discutem que a sexualidade da mulher brasileira contemporânea está presa na ambiguidade do discurso progressista e dos modelos tradicionais - parceiras heterossexuais românticas; Lia, ao mesmo tempo em que rompeu com o primeiro casamento, só foi para outro quando encontrou um homem que "prestava" - um evangélico. Para ela, todo homem trai, é instintivo; dizia para as filhas: "Tenham cuidado com namorado, que namorado só quer aproveitar... Homem não presta!", o que por vez denuncia a força das estruturas de dominação de gênero, objetivada, para Lia, na vivência intergeracional de matrimônios com relacionamentos extraconjugais masculinos.

A família, como sistema que se move através do tempo, compreende todo o sistema emocional de pelo menos três gerações (Carter, McGoldrick et al., 2001), nas quais os relacionamentos interpessoais subjetivamente interagem num dialético processo de manutenção e desconstrução. Isso aparece para Lia nas seguintes falas: "Às vezes ela sofria também com a mãe dela, né. Ela também batia nela..." (sobre a mãe ser meio fechada). E traz ainda: "Eu imaginava: o dia que eu sofrer no casamento, eu não vou ser Lia. Aquilo dentro de mim... Via minha mãe sofrer...". Para suas filhas, o modelo intergeracional chega como uma possibilidade: "Como é que a mãe conseguiu largar e casar de novo? Então quando elas viram que eu consegui, elas fizeram o mesmo". Duas de suas filhas estão no segundo casamento. Por fim, Lia comenta que se perguntasse o que ensinou para suas filhas, diriam: "Ai a mãe ensinou nós a mandar no marido!'; hoje, inversamente ao primeiro casamento, é Lia quem dá a última palavra.

Rosa, por sua vez, manteve o casamento, com muita paciência, tal qual sua mãe. O relato abaixo ilustra seu processo identificatório com o lugar socialmente instituído para o feminino aliado à sua experiência na família de origem (Testoni \& Tonelli, 2006):

\begin{abstract}
Acho que eu vivi bem com ele sabe por quê? Por que eu sou uma pessoa muito assim... Como se diz? Sei lá, dependente dele. Por que eu casei; não tinha dinheiro pra nada, só criar filho e trabalhar! Nunca tinha liberdade pra nada, né; nem pra sair de casa! Por que se eu saisse e demorasse um pouquinho já ficava bravo... É dificil, né? Mas... Sofri muito! E meu pai também era meio bravo, sabe? Exigia muito da gente, acho que acostumei com o ritmo, né! ... Eu sempre fui muito forte.
\end{abstract}

Essa fala explicita também um padrão cultural, no qual se esperava que a mulher ficasse "atrás" do homem, cuidando da família - paradoxalmente tendo que viver sem qualquer tipo de apoio emocional ("ser forte"); em que ainda a adaptabilidade era exigida para lidar com a falta de comunicação e indisponibilidade do marido (Carter, McGoldrick et al., 2001).
Para Saffioti (1991), a relação permeada pelo poder do macho, na qual a mulher está para lhe servir, impede a troca, a reciprocidade de prazer. Assim, observa-se presente na biografia de Rosa certo sofrimento pela impossibilidade de exercer o direito de ir e vir, de ter domínio sobre seu próprio corpo - uma vida limitada à esfera familiar/doméstica. Sobre o casamento, desabafa:

Sentia assim, que era assim meia - era uma mulher que é levar pra cama, forno e fogão! Não é assim, ele nunca me convidava pra passear, pra ir numa parte de criatividade... SESC! Coisa nenhuma, sabe! Era só ali ó: trabalhar, cuidar dos filhos... Eu queria que ele; eu tinha vontade às vezes eu falava para ele que a gente tinha que sair - "Como que ce vai sair com essa criançada?" Algum jeito tinha que dar, ele não saía pra trabalhar? Mas ele nunca fez força...

Por outro lado, a postura de Rosa, de esperar uma atitude do marido, vem imbuída de uma resignação feminina, na qual a passividade sobrepõe-se à ação. Como gênero é uma categoria relacional, ao posicionarse dessa forma, Rosa manteve a assimetria de poder da relação conjugal.

Já Lia tomou outro rumo frente às limitações do primeiro casamento. Ainda que o sofrimento the trouxesse forças para sair daquela situação e lutar pela sua felicidade, levou pelo menos dez anos para se "empoderar" - desde que descobriu que o ex-marido tinha amante, ficou "agüentando" [iㅗ] sem gostar dele: "Se eu lutasse muito eu conseguia, mas não, aceitei...". O conceito "tempo de morrer" ${ }^{10}$, descrito por Sawaia (1995), pode ser aqui emprestado para Lia, quando vivia aprisionada ao medo das ameaças do marido; em contrapartida, seu "tempo de viver" veio com a ruptura desse casamento, onde se viu livre para ser feliz. Indo atrás da sua independência financeira, pôde criar um novo caminho que significasse sua vida, transformandose em dona da sua história.

Em seu trilhar, Rosa, de família simples e tradicional, não imaginava ter uma profissão; nascida e criada no mato, diz que não tinha motivo pra ter ideia. Buscou, desse modo, afirmar sua posição social através da maternidade - sem "escolha" sobre seu corpo, pariu onze vezes. $O$ valor da maternidade atravessa sua história como cuidadora, primeiro dos filhos, depois do marido doente, hoje da netinha. Ao mesmo tempo, Rosa está envolvida com a comunidade da igreja, sai para caminhar todos os dias e tem muita disposição de viver - encara ainda longas viagens de ônibus para visitar parentes - só não viaja à noite, pois os homens não respeitam (um já tentou lhe passar a mão no ônibus). Segura de si, ela reconhece que sua vida não foi um mar de rosas, contudo, demonstra muita alegria de viver; o que talvez não se apercebesse num rápido olhar sobre 
sua história, pautada na dependência econômica do marido. Subjetividades que remetem ao caráter singular e irredutível de cada trajetória.

Numa necessária aproximação à Antropologia, Siqueira (1997) traz a preocupação mais recente "em se deslocar o eixo das análises do lugar da mulher como objeto da dominação masculina, para a questão da mulher como sujeito de sua constituição enquanto ser-no-mundo e dos múltiplos agenciamentos de subjetivação que produzem diferentes subjetividades" (p. 276). Assim, cada uma significa à sua maneira os sentidos de gênero da sua história e transforma aqueles que não mais lhe significam.

Uma visão sobre as permanências e semelhanças desses sentidos para Rosa e Lia denuncia que o serviço doméstico ainda aparece como reservado à mulher, e o trabalho remunerado ao homem (com exceção do tempo que Lia precisou trabalhar fora); tanto que sobre a vantagem de ser mulher ela fala: "a vantagem é que a mulher fica mais em casa, o homem é que trabalha mais". Para Rosa, a vantagem vem sobre outro aspecto: "Mulher é mais amorosa, mais paciente...". Que, todavia, remete ao símbolo da mulher para Lia: "Mulher já é amor. Tem que dar amor pros pais, depois tem amor pro namorado, depois pro marido... amor pros filhos...". Sem se aperceberem do caráter histórico-cultural dessa concepção, Rosa e Lia reproduzem uma ideologia de gênero, que "deposita" o amor à mulher, como se homens não estivessem sujeitos a amar, a cuidar...

A dimensão da saúde também vem enriquecida pelos relatos - como exemplo, o não acesso a um planejamento familiar adequado para Rosa fere uma questão de cidadania e sinaliza uma concepção de gênero e poder implicadas no cotidiano e no acesso aos serviços de saúde. Como diz Sawaia (1995): "saúde é uma questão eminentemente sócio-histórica e, portanto, ética, pois é um processo da ordem da convivência social e da vivencia pessoal" (p. 157). Logo, esta compreensão abrange a maneira pela qual o individuo se relaciona com o mundo social a que pertence. Lia explicita isso nesta conversa sobre as desvantagens de ser mulher: "As desvantagens da mulher é a saúde. A mulher tem menos saúde que os homens, né. A menstruação... É ter neném..." - Ter neném é ter menos saúde? "É; a mulher perde a saúde. Eu. Agora não, mas naquele tempo a mulher engravidava, ficava doente, não ia no médico; eu sofri muito.... A gente pensava que tinha que sofrer mesmo; eu sofri muito". Nessa fala transparecem subjetividades que denotam relações assimétricas de poder e de gênero, na qual, a mulher, vista como "inferior", tinha que sofrer, e o médico, homem, era aquele que amenizava o sofrimento. Ao mesmo tempo, em outro momento, Lia traz uma visão emancipatória da mulher, como quando assinala o "ser forte" para sair do casamento; enfim, múltiplos agenciamentos de gênero que expressam o caráter essencialmente dinâmico das dimensões sociais e denunciam que, nas diferentes trajetórias de vida, ambiguidades e contradições convivem em meio a novas lógicas, tornando o sujeito capaz de, dialeticamente, transformar seu cotidiano (Testoni \& Tonelli, 2006).

De maneira geral, sobre as mudanças dos sentidos de gênero, Rosa e Lia dizem que a vida das mulheres melhorou, trazem o estudo como valor e se sentem bem como mulher, tal qual na pesquisa da FPA. Indo além, essas falas denunciam toda uma história de luta em prol da mulher - dar-se conta dessas subjetividades latentes identifica um compromisso com a transformação social; o que não poderia ser diferente na saúde.

No entanto, na ESF a abordagem à família não se configura padronizada, implicando que cada profissional a faça a seu modo; isso gera múltiplas abordagens, do indivíduo ao social, que acabam por compor um quadro de diversidade/parcialidades que dificulta o acesso à integralidade (Ribeiro, 2004). Dessa forma, gênero ${ }^{11}$ se apresenta como um caminho que amplifica $o$ olhar para as desigualdades (micro e macro) e pode ser um fio condutor adequado à proposta da ESF, ao conscientizar os profissionais de saúde da sua co-construção dos sentidos de gênero, impulsionando, assim, ações mais efetivas à integralidade. No trabalho em Saúde da Família, a mulher não pode ser vista a priori como mãe, antes como mulher e, sobretudo, como Sujeito. E, sendo o psíquico tão importante quanto o físico (Sawaia, 1995), a integralidade deve ser movida pela ética da solidariedade e do reconhecimento do outro como merecedor de compaixão (Costa \& Silvestre, 2004), seja ele quem for.

Logo, as histórias de Lia e Rosa podem nos ajudar a ir além da exclusão e da dominação na nossa práxis em saúde, para que assim, tal qual suas filhas hoje, cada ser humano possa plenamente exercer o direito de escolha sobre seus corpos e vidas.

\section{Considerações Finais}

As trajetórias dessas mulheres, tecidas em meio a tensões culturais, políticas e religiosas do que significa ser mulher, estão permeadas de lutas e desafios frente às diversidades de um mundo que, em meios a avanços, ainda se encontra dominado pelo universo masculino; frente às escolhas em relação ao seu corpo biológico; frente às suas próprias indagações.

Lia e Rosa trazem as marcas do pré e do pósfeminismo em suas histórias, e fazem parte de um novo cenário da saúde pública, de uma outra luta, a da Reforma Sanitária. Nesta perspectiva, o movimento feminista precisa recuperar o debate sobre as necessi- 
dades de saúde das mulheres, alinhando-se à Reforma Sanitária em prol da integralidade. Do mesmo modo, para transformar o modelo assistencial, a ESF necessita enxergar as questões de gênero infiltradas no cotidiano do trabalho em saúde, de maneira a refletir como se engendram as relações de gênero e poder entre profissionais de saúde $x$ usuários, entre os próprios profissionais, bem como nas políticas públicas de saúde.

Em sua práxis, a ESF pode favorecer espaços de escuta, reflexão e questionamento das práticas de dominação e exclusão, que se reproduzem no cotidiano dos relacionamentos afetivo-conjugais em suas diferentes configurações. Tais reproduções são igualmente perpetuadas pelas próprias mulheres, que muitas vezes não se dão conta de como elas se processam ${ }^{12}$. Nesta instância, o "empoderar-se" implica ter consciência das condições sócio-históricas que se inserem em suas trajetórias, de como emocionalmente interagem com aquelas, bem como vivenciam e escrevem suas histórias. Muito mais, além disso, é saber dos seus direitos e deveres, é lutar para o acesso de todos aos serviços de saúde, é não se intimidar frente à violência masculina; e sim, compreendendo que as barreiras derrubadas são fruto de determinação pessoal e esforço coletivo, ainda há o que se trilhar na conquista da cidadania feminina. Se bem que as transformações até agora conquistadas apontam um caminho para a construção de novas relações de gênero não-assimétricas, não só no que diz respeito ao relacionamento de homens e mulheres, como também para as diversas manifestações de afetividade que se apresentam.

\section{Notas}

${ }^{1}$ Este artigo foi elaborado como requisito parcial para a Residência Multiprofissional em Saúde da Família da Faculdade Evangélica do Paraná.

${ }^{2}$ Este se admite ser "aquele que confronta incisivamente racionalidades hegemônicas no sistema” (Alves, 2005, p. 41).

${ }^{3}$ A partir do Movimento da Reforma Sanitária a saúde passa a ser concebida como um produto social, ou seja, depende também de outras políticas sociais, como emprego, habitação e educação (Costa \& Silvestre, 2004). Fundamentada nos princípios do SUS - universalidade, equidade, integralidade, regionalização, hierarquização, descentralização e controle social - esse movimento, cujas palavras de ordem são direito à saúde e cidadania, busca reorganizar e democratizar a saúde pública, colocando a unidade de saúde como porta de entrada para o SUS

${ }^{4}$ A teoria dos ciclos de vida e o genograma são alguns dos recursos teórico-práticos dessa abordagem também utilizados como ferramentas do PSF.

${ }^{5}$ Não por acaso, nas décadas de 50-60, os autores americanos da terapia familiar eram homens, brancos e de classe média, que foram limitados pela visão hegemônica da época (Rampage \& Avis, 1998)
6 "A Mulher Brasileira nos Espaços Público e Privado" - Pesquisa realizada com 2502 mulheres com mais de 15 anos, por meio de questionários e entrevistas, em outubro de 2001; organizada por Venturi, Recamán e Oliveira (2004).

${ }^{7}$ A Pesquisa Nacional por Amostragem de Domicílios PNAD/2003 - revelou que dos 139,5 milhões de brasileiros (79,3\% da população) que dispunham de um serviço de saúde regular, os postos de saúde foram a modalidade mais citada para $52,4 \%$ dos entrevistados, sendo mais buscados pelas mulheres $(58,9 \%)$ do que pelos homens $(52,5 \%)$; enquanto a proporção masculina era maior entre os que se dirigiam aos ambulatórios de hospitais (17,2 contra 16,6 para as mulheres). O tipo de serviço utilizado como porta de entrada variou segundo a idade, o sexo e o rendimento mensal familiar. Os postos de saúde e os ambulatórios de hospitais foram referidos com maior frequência como serviços de saúde de uso regular à medida que o rendimento mensal familiar caía; sendo aqueles referidos com mais frequência pelas pessoas menores de 19 anos, do sexo feminino e das classes de renda mensal familiar mais baixas (IBGE, 2005, p. 44).

${ }^{8}$ Alguns desses programas são: o Saúde da Mulher, o Programa Nacional de Controle do Câncer do Colo do Útero e de Mama - Viva Mulher e o Programa de Atenção Humanizada ao Parto / Nascimento.

${ }^{9}$ Do inglês: Empowerment.

${ }^{10}$ Em um trabalho de Sawaia com mulheres socialmente desfavorecidas, a expressão "tempo de morrer" foi utilizada por elas para caracterizar a falta de recursos emocionais, de força para pensar e agir, o desânimo em relação à própria competência - sofrimento, angústia. Já "tempo de viver" "é o tempo de agir com mais coragem e audácia, é tempo em que se despertam as emoções, quer sejam elas positivas ou negativas... Um tempo de convite à vida, mesmo sendo uma vida sofrida" (Sawaia, 1995, p. 159).

${ }^{11}$ Saffioti (2004) deflagra que gênero, raça/etnia e classe social é o tripé contraditório no qual se apoia a antidemocracia brasileira (pelas relações de dominação/exclusão presentes em cada uma das hastes deste tripé).

${ }^{12}$ Lia contou que no tempo de casada não conversava com outras mulheres - não sabia o que era certo em relação ao casamento. Sugeriu ainda como atividade de saúde para as mulheres, dança e grupos que "as mulher se juntasse e fosse conversar" (tal qual sugerido pelas feministas pioneiras).

\section{Referências bibliográficas}

Alves, V. S. (2005). Um modelo de educação em saúde para o Programa Saúde da Família: pela integralidade da atenção e reorientação do modelo assistencial. Interface, 9(16), 39-52.

Araújo, M. de F. (2005). Diferença e igualdade nas relações de gênero: revisitando o debate. Psicologia Cínica, 17(2), 41-52.

Carter, B., McGoldrick, M. et al. (2001). As mudanças no ciclo de vida familiar: uma estrutura para a terapia familiar $\left(2^{\mathrm{a}}\right.$ ed.). Porto Alegre: Artes Médicas.

Chacham, A. S. \& Maia, M. B. (2004). Corpo e sexualidade da mulher brasileira. In G. Venturi, M. Recamán, \& S. de Oliveira (Orgs.), A mulher brasileira nos espaços público e privado (pp.75-86). São Paulo: Fundação Perseu Abramo.

Costa, A. M. \& Silvestre, R. M. (2004). Uma reflexão sobre 
poder, mulher e saúde: dilemas para a saúde reprodutiva. In G. Venturi, M. Recamán, \& S. de Oliveira (Orgs.), A mulher brasileira nos espaços público e privado (pp.62-74). São Paulo: Fundação Perseu Abramo.

Farah, M. F. S. (2004, janeiro/abril). Gênero e políticas públicas. Estudos Feministas, 12(1), 47-71.

Fonseca, T. M. G. (1997). Psicologia e relações de gênero: o gênero da ciência psicológica. In A. V. Zanella, M. J. T. Siqueira, S. Molon, \& L. do A. Lulhier (Orgs.), Psicologia e práticas sociais (pp. 317-322). Porto Alegre: ABRAPSOSUL.

Fundação Carlos Chagas. Banco de dados sobre o trabalho das mulheres. Acesso em 26 de janeiro, 2007, em http://www. fcc.org.br/mulher/

Instituto Brasileiro de Geografia e Estatística (2005). Pesquisa Nacional por Amostragem de Domicílios (PNAD) - Acesso e utilização de serviços de saúde 2003. Rio de Janeiro: Autor.

Meneghel, S. N., Barbiani, R., Brener, C., Teixeira, G., Sttefen, H., Silva, L. B. da, et al. (2005). Cotidiano ritualizado: grupos de mulheres no enfrentamento à violência de gênero. Ciência \& Saúde Coletiva, 10(1), 111-118.

Minayo, M. C. de S. (2004). O desafio do conhecimento: pesquisa qualitativa em saúde ( $8^{\mathrm{a}}$ ed.). São Paulo: Hucitec.

Narita, S. (2006, maio/agosto). Notas de pesquisa de campo em psicologia social. Psicologia \& Sociedade, 18(2), 25-31.

Nuernberg, A. H. (2004). Gênero, psicologia social e interdisciplinaridade. In M. C. de S. Lago, M. P. Grossi, C. T. da C. Rocha, O. R. Z. Garcia, \& T. Sena (Orgs.), Interdisciplinaridade em diálogos de gênero: teorias, sexualidades, religiões (pp. 209-227). Florianópolis: Mulheres.

Rago, M. (2004). Ser mulher no século XXI ou Carta de Alforria. In G. Venturi, M. Recamán, \& S. de Oliveira (Orgs.), A Mulher brasileira nos espaços público e privado (pp. 31-42). São Paulo: Fundação Perseu Abramo.

Rampage, C. \& Avis, J. M. (1998). Identidade sexual, feminismo e terapia familiar. In M. Elkaïm (Org.), Panorama das Terapias Familiares - 2 (pp. 189-221). São Paulo: Summus.

Ribeiro, E. M. (2004). As várias abordagens da família no cenário do programa/Estratégia de saúde da família (PSF). Revista Latino-Americana de Enfermagem, 12(4), 658-664.

Saffioti, H. I. B. (1991). O Poder do macho (5 ed.). São Paulo: Moderna.

Saffioti, H. I. B. (2004). Gênero e patriarcado: violência contra as mulheres. In G. Venturi, M. Recamán, \& S. de Oliveira (Orgs.), A mulher brasileira nos espaços público e privado (pp. 43-59). São Paulo: Fundação Perseu Abramo.

Sarti, C. A. (2004, maio/agosto). O feminismo brasileiro desde os anos 1970: revisitando uma trajetória. Estudos Feministas, $12(2), 35-50$.

Sawaia, B. B. (1995). Dimensão ético-afetiva do adoecer da classe trabalhadora. In S. T. M Lane \& B. B Sawaia (Orgs), Novas veredas da psicologia social (pp. 156-168). São Paulo: Brasiliense (Educ).

Scott, J. (1990, julho/dezembro). Gênero: uma categoria útil de análise histórica. Educação \& Sociedade, 16(2), 5-22.

Siqueira, M. J. T. (1997). A(s) psicologia(s) e a categoria gênero: anotações para discussão. In A. V., Zanella; M. J. T Siqueira, S. Molon, \& L. do A. Lulhier (Orgs.), Psicologia e práticas sociais (pp. 271-279). Porto Alegre: ABRAPSOSUL.

Soares, V. (2004). O feminismo e o machismo na percepção das mulheres brasileiras. In G. Venturi, M. Recamán, \& S. de Oliveira (Orgs.), A mulher brasileira nos espaços público e privado (pp. 161-182). São Paulo: Fundação Perseu Abramo.
Sorj, B. (2004). Trabalho remunerado e trabalho não remunerado. In G. Venturi, M. Recamán, \& S. de Oliveira (Orgs.), A mulher brasileira nos espaços público e privado (pp. 107-119). São Paulo: Fundação Perseu Abramo.

Testoni, R. J. F. \& Tonelli, M. J. F. (2006, janeiro/abril). Permanências e rupturas: sentidos de gênero em mulheres chefes de família. Psicologia \& Sociedade, 18(1), 40-48.

Venturi, G. \& Recamán, M. (2004). Introdução: as mulheres brasileiras no início do século XXI. In G. Venturi, M. Recamán, \& S. de Oliveira (Orgs.), A mulher brasileira nos espaços público e privado (pp. 15-30). São Paulo: Fundação Perseu Abramo.

Ana Priscila de Oliveira Benites é psicóloga pela UFSC, terapeuta familiar sistêmica pelo INTERCEF (Curitiba) e especialista em Saúde da Família/ modalidade Residência pela Faculdade Evangélica do Paraná (FEPAR). Endereço para correspondência: Alameda Leopoldo Schmalz, 68.

Vorstadt. Blumenau-SC. CEP 89015-445.

E-mail: anapriscila_benites@yahoo.com.br

Neuzi Barbarini é mestre em Psicologia Social e Institucional pela UFRGS. Atualmente é professora da PUC/PR e Faculdade Dom Bosco/PR. Endereço para correspondência: Rua Conselheiro Laurindo, 63. Ap. 14. Centro. Curitiba/PR Cep 80060-100. E-mail: neuzib@gmail.com

Histórias de vida de mulheres e saúde da família: algumas reflexões sobre gênero

Ana Priscila de Oliveira Benites e Neuzi Barbarini

Recebido: 26/02/2008

$1^{\text {a }}$. Revisão: 08/05/2008

Aceite final: 03/06/2008 